\title{
EDTA-modified mesoporous silica as supra adsorbent of copper ions with novel approach as an antidote agent in copper toxicity
}

This article was published in the following Dove Press journal: International Journal of Nanomedicine

\author{
Elham Rafiee Taqanaki' \\ Reza Heidari iD ${ }^{2}$ \\ Mohammad Monfared (iD) 1,3 \\ Lobat Tayebi iD $^{4}$ \\ Amir Azadi ${ }^{2,5}$ \\ Fatemeh Farjadian (1D) ${ }^{2}$ \\ 'Department of Medical \\ Nanotechnology, School of Advanced \\ Medical Sciences and Technologies, Shiraz \\ University of Medical Sciences, Shiraz, \\ Iran; ${ }^{2}$ Pharmaceutical Sciences Research \\ Center, Shiraz University of Medical \\ Sciences, Shiraz, Iran; ${ }^{3}$ Student Research \\ Committee, Shiraz University of Medical \\ Sciences, Shiraz, Iran; ${ }^{4}$ School of \\ Dentistry, Marquette University, \\ Milwaukee, WI, USA; ${ }^{5}$ Department of \\ Pharmaceutics, Faculty of Pharmacy, \\ Shiraz University of Medical Sciences, \\ Shiraz, Iran
}

Correspondence: Fatemeh Farjadian

Pharmaceutical Sciences Research Center Faculty of Pharmacy, Shiraz University of Medical Sciences, P.O. Box 7|345-I583,

Shiraz, Iran

Tel +987 II 32424 I 27 (302)

Fax +987132424126

Email farjadian_f@sums.ac.ir

Amir Azadi

Pharmaceutical Sciences Research Center Department of Pharmaceutics, Faculty of

Pharmacy, Shiraz University of Medical

Sciences, Shiraz, Iran

Tel +987 II 32424 I 27 (286)

Fax +98 7I3 2424126

Email aazadi@sums.ac.ir
Purpose: Mesoporous silica (MS) have been considered as a biocompatible compound and found to have various pharmaceutical applications. Recently, novel approaches in applications of MS as antidote agents were introduced. In this study, the capacity of ethylenediaminetetraacetic acid modified mesoporous silica (MS-EDTA) was evaluated in in vitro and in vivo adsorption of copper $(\mathrm{Cu})$.

Methods: The MS-EDTA was characterized by fourier transform infrared (FT-IR) and X-ray diffraction, while surface area was determined by $\mathrm{N}_{2}$ adsorption-desorption technique. Morphological studies were observed by high resolution-transmission electron microscopy and field emission-scanning electron microscopy and the sizes were determined by dynamic light scattering. The capacity of these particles for copper adsorption was investigated in vitro in both 1.2 and $7.2 \mathrm{pH}$. In in vivo animal study, the $\mathrm{Cu}$ adsorption efficiency of MSEDTA in $\mathrm{Cu}$-overdosed mice was evaluated. In this case, an animal model of acute copper poisoning was prepared.

Results: The MS-EDTA with surface area of 352.35 was synthesized. Scanning electron microscope showed spherical particle formation with less than $500 \mathrm{~nm}$ in size. Transmission electron microscope images showed porous and honeycomb structure. FT-IR spectroscopy showed an appropriate formation of functional groups. Particle efficiency was investigated for $\mathrm{Cu}$ adsorption. MS-EDTA in both media showed a high adsorption capability for $\mathrm{Cu}$ (II) adsorption in $\mathrm{pH}=1.2$ and $\mathrm{pH}=7.2$. In addition, the study of Langmuir, Freundlich, and Redlich-Peterson adsorption models showed that copper adsorption by MS-EDTA followed the Freundlich model with multi-layer adsorption. In vivo evaluation showed that MS-EDTA could alleviate the symptoms of acute copper poisoning by lowering $\mathrm{Cu}$ plasma levels.

Conclusion: Structural evaluation showed successful formation of MS-EDTA. In vitro analysis demonstrated that supreme $\mathrm{Cu}$ adsorption occurs in both $\mathrm{pH}$ conditions $(7.2$ and 1.2), and was especially more favorable in simulated intestinal $\mathrm{pH}$ (7.2). The in vivo studies in animal models with acute $\mathrm{Cu}$ poisoning showed that MS-EDTA could be a potent antidote agent.

Keywords: mesoporous silica, antidote, copper, intoxication, EDTA, in vivo

\section{Introduction}

Physicochemical features of nanoscale materials and structures, including surface-tovolume ratio, surface chemistry, optical, electrical, thermal, and magnetic properties, make nanotechnology beneficial for medical and pharmaceutical purposes. ${ }^{1}$ Having a technology with the ability of controlled absorption, carry, release, sensing, and/or separation of certain substances (such as drugs or therapeutic agents) in vivo or ex 
vivo is worthwhile to gain diagnostic or therapeutic goals. ${ }^{2,3}$ To achieve this, requires biocompatible particles with identical sizes, adjustable pore sizes and volumes, large interacting surface area, and acceptable capacity of functionalization, desirable biodistribution, lifetime, and toxicity. ${ }^{4,5}$ Liposomes, ${ }^{6}$ micelles, ${ }^{7}$ dendrimers, ${ }^{8}$ magnetic nanoparticles, ${ }^{9}$ gold nanoparticles, ${ }^{10}$ quantum dots, ${ }^{11}$ and carbon nanotubes $^{12}$ are those which may present some, but not all, of these features. However, porous materials are capable of displaying these necessary features. ${ }^{13}$

Mesoporous solid particles' surface area is absolutely enormous; in some cases, reaching $1000 \mathrm{~m}^{2} \mathrm{~g}^{-1} .14$ Mesoporous silica nanoparticles (MSNs) are size-tunable nanoparticles that possess well-ordered pores with sizes of 2-50 $\mathrm{nm}$ and a large surface area that can be functionalized or interact with drugs, ions or other molecules. ${ }^{15}$ Silica is used as a food additive and in cosmetics, and also has been categorized as "Generally Recognized as Safe" by FDA. ${ }^{16}$ Moreover, several studies have been shown that MSNs have high biocompatibility and that some specific doses (up to $100 \mu \mathrm{g} \cdot \mathrm{mL}^{-1}$ ) do not have any toxicity. ${ }^{15}$ For instance, Qianjun et al, evaluated the effects of MSN size on in vivo biodistribution and urinary excretion and concluded that MSNs with different particle sizes (80-360 nm) accumulate mainly in the liver and spleen with a minority of them in the lungs and a few in the kidney and heart and also that MSNs cause no tissue toxicity after 1 month. ${ }^{17}$

MSNs have tunable pores with high surface area and good functionality, making them a desirable encasement for a wide range of molecules. ${ }^{18}$ MSNs can be synthesized by different chemical methods using either hard or soft and organic or non-organic templates, but mostly is completed by soft templates, such as block copolymers and surfactants that are amphiphilic molecules. ${ }^{15}$ Structure, composition, pore size and volume, and functional groups can be designed and tailored during synthesis by controlling moieties stoichiometry, surfactant types, and reaction conditions. ${ }^{19}$ Therefore, different types of MSNs have been synthesized and studied, including MCM-41 (Mobil Composition of Matter/No. 41), MCM-48 (Mobil Composition of Matter/ No. 48), MCM-50 (Mobil Composition of Matter/No. 50) MCM-48, HMS (hexagonal mesoporous silica), SBA-15 (Santa Barbara Amorphous), and so on. ${ }^{20}$

MCM-41 is an ordered and uniform two-dimensional mesoporous silica (MS) that is widely studied. Cetyl-trimethylammonium bromide (CTAB) is the surfactant commonly used to synthesize MCM-41. ${ }^{21}$ Generally, nano-sized particles (e.g. MSNs) internalize into cells by endocytosis, and the internalization pathway is highly dependent on structural and chemical properties of nanomaterials such as shape, size, and surface functionalization. There is some evidence that suggests clathrinmediated endocytosis and caveolae-mediated endocytosis as the main internalization route of $\mathrm{MSN}^{15}$ Altogether, MSNs are one of the best potential candidates for applications such as catalysis, ${ }^{22}$ sensors, ${ }^{23}$ drug delivery systems, ${ }^{24}$ imaging agents, ${ }^{25}$ separation, ${ }^{26}$ microextraction, ${ }^{27}$ and as potent adsorbent. ${ }^{28}$

A therapeutic substance that counteracts the toxicity mechanisms of a specified xenobiotic is an antidote. Antidotes are playing an important role in the treatment of poisoning. ${ }^{29}$ Recently, MSNs have also been used as an antidote agent that can adsorb toxic agents in or out of cells. In the study that was conducted by Farjadian et al, MCM-41 was used as potential adsorbent of acetaminophen and phenobarbital while showed a better performance compared to activated charcoal that was the traditional method. ${ }^{30}$ Subsequently, in 2017, ethylenediaminetetraacetic acid (EDTA)-modified MSN was used to remove iron toxicity in an animal model. ${ }^{31}$ MS materials have shown high potential in heavy metals adsorption. In a study MS, iron oxide nanocomposites were used to remove heavy metals, with successful results in adsorbing $\mathrm{Ni}, \mathrm{Cd}, \mathrm{Cr}, \mathrm{Zn}$, and $\mathrm{Pb}$ ions. ${ }^{32}$ Also, EDTA-modified MSNs were used to adsorb $\mathrm{Pb}$ in different $\mathrm{pH}$, and a favorable adsorption performance was gained as a result. $^{33}$

Wilson disease is an autosomal recessive disorder caused by a mutation in the ATP7B gene ${ }^{34}$ with a relative prevalence of one in every 30,000 births. ${ }^{35}$ Copper is accumulated in various organs and tissues, such as the liver and brain, ${ }^{36}$ and can induce a wide range of symptoms, such as brain disorders. ${ }^{35}$ The usual drug for this disease is oral Dpenicillamine, a chelating agent for copper.

Although this drug can adsorb extra copper, many side effects have been observed with its use, including immunologic reactions, skin lesions (such as epidermolysis bullosa), systemic lupus erythematosus, nephrotic syndrome, Goodpasture syndrome, Ehlers-danlos syndrome, myasthenia gravis, polymyositis, and thrombocytopenia. Also, in some patients, clinical symptoms such as dystonia and Parkinson have been seen with penicillamine consumption. ${ }^{37}$

Recent studies on antidotes have shown that functionalized MSNs can be applied as an appropriate antidote for overdose of iron. Farjadian et al, sought to adsorb iron by using MSN-EDTA and has provided great results. ${ }^{31}$ It is 
predicted that MSNs could adsorb other metals, such as copper, and therefore, one could contemplate their use as a suitable antidote for copper in copper toxicity. This study aims to synthesize and evaluate the kinetics and isotherms of EDTA-functionalized mesoporous silica particles (MSEDTA) as an adsorbent of $\mathrm{Cu}(\mathrm{II})$ in gastrointestinal $\mathrm{pH}$ simulated in vitro conditions and $\mathrm{Cu}$-overdosed mice.

\section{Methods and materials}

\section{Materials}

CTAB, tetraethoxysilane (TEOS), 3-aminopropyl triethoxysilane (APTES), thionyl chloride $\left(\mathrm{SOCl}_{2}\right)$, copper sulfate pentahydrate $\left(\mathrm{CuSO}_{4} .5 \mathrm{H}_{2} \mathrm{O}\right)$, dimethyl sulfoxide (DMSO), and ethylenediaminetetraacetic acid were purchased from Merck chemical company (Sigma-Aldrich). Hydrochloric acid $(\mathrm{HCl})$, ethanol, and acetone were bought from Kimia Mavad (Tehran, Iran).

\section{Preparation of amino-functionalized MCM-4I (MS-NH $\left.{ }_{2}\right)$}

MS-NH $\mathrm{N}_{2}$ was prepared according to a reported procedure. ${ }^{38}$ Briefly, $6.6 \mathrm{mmol}$ of CTAB was dissolved in $100 \mathrm{~mL}$ of $1: 1$ deionized (DI) water/ethanol solution, then $13 \mathrm{~mL}$ of ammonia was added. After obtaining a clear solution, $3.085 \mathrm{~mL}$ of TEOS and $0.37 \mathrm{~mL}$ of APTES was added dropwise to the solution over 10 mins while stirring. The solution was stirred for $2 \mathrm{hrs}$ at $80^{\circ} \mathrm{C}$ to produce a white mixture. The product was washed three times with DI water and ethanol, then was dried overnight (at $60^{\circ} \mathrm{C}$ ) in an oven. Acidic ethanol (6 mL HCl/200 mL ethanol) was used to extract the surfactant templates $\left(48 \mathrm{hrs}, 90^{\circ} \mathrm{C}\right)$.

\section{Preparation of EDTA-functionalized MCM-4I (MS-EDTA)}

The preparation of MS-EDTA was performed according to the reported procedure. $^{31}$ Briefly, $1.7 \mathrm{~g}$ EDTA was dissolved in $20 \mathrm{~mL}$ of DMSO, then $0.42 \mathrm{~mL}$ of thionyl chloride $\left(\mathrm{SOCl}_{2}\right)$ was added dropwise. After $10 \mathrm{mins}, 1$ $\mathrm{g}$ of $\mathrm{MS}-\mathrm{NH}_{2}$ was added to the solution and stirred for 20 hrs at room temperature. Samples were centrifuged $(3 \times 10$ mins, $5000 \mathrm{rpm}$ ) and washed three times with ethanol and acetone, then dried by freeze-dryer.

\section{Characterization}

Morphology of particles was characterized by high resolution-transmission electron microscopy (HR-TEM) by JEOL JEM 2010 instrument. Field emission-scanning electron microscopy (FE-SEM) was performed with Zeiss Merlin PV instrument to determine the size of particles and energy-dispersive X-ray spectroscopy (EDX) to determine the type of elements in the sample. Dynamic light scattering (DLS), by Microtrac, was used to determine hydrodynamic diameter. Fourier transform infrared spectroscopy (FT-IR) with KBr by BRUKER (Germany) was performed to obtain an infrared spectrum of absorption or emission of particles, X-ray diffraction (XRD) was performed by $40 \mathrm{kV}$ MPD 3000 instrument to obtain detailed information about structure properties. Copper adsorption by MS-EDTA was investigated by Varian atomic absorption spectroscopy (AAS). Physical and chemical composition of particles and also the Brunauer Emmett Teller (BET) technique have been performed by Micromertics TriStar II plus (America) to measure particles surface area.

\section{Adsorption tests}

To determine the copper adsorption by MS-EDTA, samples containing $\mathrm{CuSO}_{4} / \mathrm{MS}$-EDTA with concentration ratios of $\mathrm{CuSO}_{4}(\mathrm{mmol}) / \mathrm{MS}-\mathrm{EDTA}\left(\mathrm{NH}_{2}+\mathrm{EDTA}\right) \mathrm{mmol}$ : $0.2,0.5,1,2.5,5,7.5,10,50,150,500,1000$, and 25,000 were prepared in $\mathrm{pH}=1.2$ and $\mathrm{pH}=7.2$ mediums. Samples were mixed at $40^{\circ} \mathrm{C}$ for $2 \mathrm{hrs}$ in a shaker. After adsorption, the samples were investigated by AAS.

To determine the copper adsorption isotherm adsorption capacity, Equation 1 was utilized:

$$
\mathrm{q}=\left(\mathrm{C}_{0}-\mathrm{C}_{\mathrm{e}}\right) \mathrm{V} / \mathrm{m}
$$

In this equation, $\mathrm{m}(\mathrm{g})$ is the sorbent's mass (MS-EDTA). $\mathrm{C}_{0}\left(\mathrm{mmol} \mathrm{L}^{-1}\right)$ is the initial concentration of copper, $\mathrm{C}_{\mathrm{e}}$ (mmol L ${ }^{-1}$ ) is the concentration of copper at equilibrium, $\mathrm{V}(\mathrm{L})$ is solution volume, and $\mathrm{q}$ is the amount of copper adsorption per MS.

\section{Adsorption isotherm models}

Three adsorption models Langmuir, Freundlich, and Redlich-Peterson were applied to fit with derived amounts of adsorbed copper mass (mmol per gram) of MS-EDTA. ${ }^{39,40}$ The Langmuir isotherm model is based on Equation 2, which is describing a continuous monolayer adsorption process surrounding homogeneous solid adsorbent.

$$
\mathrm{q}=\mathrm{q}_{\mathrm{m}} \mathrm{K}_{1} \mathrm{C}_{\mathrm{e}} /\left(1+\mathrm{K}_{\mathrm{l}} \mathrm{C}_{\mathrm{e}}\right)
$$

In the equation mentioned above, $\mathrm{q}(\mathrm{mmol} / \mathrm{g})$ is the adsorbed copper mass (mmol) of MS-EDTA $\left(\mathrm{g}^{-1}\right)$ at equilibrium. $\mathrm{K}_{1}$ and $\mathrm{q}_{\mathrm{m}}$ are the empirical constant of adsorption 
$\left(\mathrm{L} \mathrm{mmol}^{-1}\right)$ and $\mathrm{q}_{\mathrm{m}}$ maximum uptake amount $\left(\mathrm{mmol} \mathrm{g}^{-1}\right)$, respectively.

The Freundlich isotherm model based on Equation 3. This model is applied to characterize heterogeneous systems in multiple adsorption layers.

$$
\mathrm{q}=\mathrm{K}_{\mathrm{f}} \mathrm{C}_{\mathrm{e}}^{1 / \mathrm{n}}
$$

In this equation, $\mathrm{K}_{\mathrm{f}}$ is Freundlich adsorption constant $\left[\mathrm{mmol} \mathrm{g}^{-1}\left(\mathrm{~L} \mathrm{mmol}^{-1}\right)^{1 / \mathrm{n}}\right] .1 / \mathrm{n}$ represents adsorption intensity; when its value is between 0 and 1 , there is equal adsorption chances and energies for all active sites.

Redlich-Peterson is an isotherm model; a combination of both Langmuir and Freundlich model equations. This isotherm is based on Equation 4.

$$
\mathrm{q}=\mathrm{AC}_{\mathrm{e}} /\left(1+\mathrm{BC}_{\mathrm{e}}^{\mathrm{g}}\right)
$$

In Equation 4, $\mathrm{A}$ and $\mathrm{B}$ are the capacity and the equation constant, respectively. Also, "g" lies between 0 and 1 . If "g" was 1, this model would be the same as the Langmuir adsorption model, and if "g" value was between 0 and 1 , it would be similar to the Freundlich model.

\section{Kinetic models}

To investigate the effect of time on copper adsorption by MS (mmol g $\left.{ }^{-1}\right)$, a sample with Cu/MS-EDTA; $150(\mathrm{Cu}$ mmol/MS-EDTA mmol) was prepared. Then, adsorption kinetic models (i.e. pseudo-first-order, pseudo-secondorder, and intraparticle diffusion model) were studied to predict the rate of adsorption. The pseudo-first-order equation is described as follows:

$$
\operatorname{Ln}\left(\mathrm{q}-\mathrm{q}_{\mathrm{t}}\right) / \mathrm{q}=-\mathrm{K}_{1} \mathrm{t}
$$

In this equation, $\mathrm{q}_{\mathrm{t}}$ is the amount of $\mathrm{Cu}$ adsorbed $\left(\mathrm{mmol} \mathrm{g}^{-1}\right)$ at any time, $\mathrm{q}$ is the mass of adsorbed copper $\left(\mathrm{mmol} \mathrm{g}^{-1}\right)$ in equilibrium, $\mathrm{t}(\mathrm{min})$ and $\mathrm{K}_{1}\left(\mathrm{~min}^{-1}\right)$ is time and constant of adsorption rate at equilibrium, respectively.

Pseudo-second-order equation based on Equation 6.

$$
\mathrm{t} / \mathrm{q}_{\mathrm{t}}=1 / \mathrm{k}_{2} \mathrm{q}^{2}+1 / \mathrm{q}_{\mathrm{t}}
$$

In the equation above, $\mathrm{k}_{2}\left(\mathrm{mmol} \mathrm{g}^{-1} \mathrm{~min}^{-1}\right)$ is the adsorption rate constant at equilibrium, while $\mathrm{t}, \mathrm{q}$, and $\mathrm{q}_{\mathrm{t}}$ are defined in Equation 5.

Intraparticle diffusion model is stated in Equation 7.

$$
\mathrm{q}_{\mathrm{t}}=\mathrm{k}_{\mathrm{t}} \mathrm{t}^{1 / 2}+\mathrm{C}
$$

In Equation 7, $\mathrm{C}$ is the border layer thickness; $\mathrm{t}$ and $\mathrm{qt}$ are defined before.

\section{In vivo animal model}

The effect of MS-EDTA nanoparticles was evaluated against acute copper toxicity in mice. ${ }^{41}$ For this purpose, animals were allotted in the following groups ( $\mathrm{n}=6 /$ group): (A) Copper-treated animals which received $5000 \mathrm{mg} / \mathrm{kg}$ of copper sulfate by gavage, ${ }^{41}$ (B) Copper + MS-EDTA nanoparticles (1 mg/kg, gavage); (C) Copper + MS-EDTA nanoparticles (10 mg/kg, gavage); and (E) Copper + EDTA $(10 \mathrm{mg} / \mathrm{kg}$, gavage). The investigated antidotes were administered $2 \mathrm{hrs}$ after copper intoxication. Serum and liver tissue $\mathrm{Cu}$ levels, in addition to serum biomarkers of organ injury, were monitored $24 \mathrm{hrs}$ after copper administration. All the experiments using laboratory animals were performed in conformity with the guidelines for care and use of experimental animals approved by an ethics committee in Shiraz University of Medical Sciences, Shiraz, Iran (\#139601-74-14350). A MindrayBS-200 ${ }^{\circledR}$ chemistry analyzer (Guangzhou, China) and standard kits (Pars Azmun ${ }^{\circledR}$, Tehran, Iran) were used to measure plasma biomarkers of organ injury. ${ }^{42}$ Plasma Cu levels were measured using atomic adsorption spectroscopy.

\section{Results}

The main aim of this study was the potential application of MS-EDTA in the treatment of copper poisoning in paradigms like Wilson disease (Figure 1). For this purpose, MS-EDTA was synthesized. Firstly, MS- $\mathrm{NH}_{2}$ was prepared by the cocondensation method in the presence of a surfactant template (CTAB) in ammonia solution while TEOS and APTES were applied as silane coupling agents. To introduce EDTA into MS pore walls, the carboxyl functional group of EDTA was activated by thionyl chloride (thionyl chloride/EDTA; $1: 1$ ), and $\mathrm{MS}-\mathrm{NH}_{2}$ was admixed with activated EDTA solution to obtain MS-EDTA.

\section{Morphology and characterization of MS-EDTA}

The FT-IR spectrums show symmetric and asymmetric stretching bonds of $\mathrm{Si}-\mathrm{O}$ groups that appear at 790 and $1065 \mathrm{~cm}^{-1}$, respectively. Furthermore, the $\mathrm{N}-\mathrm{C}=\mathrm{O}$ band at $1480-1520 \mathrm{~cm}^{-1}$ and $1630 \mathrm{~cm}^{-1}$ is respectively related to amide and carboxylic acid $(\mathrm{C}=\mathrm{O})$ functional groups (Figure 2). BET calculations have shown MS-EDTA with a surface area of $352.35 \mathrm{~m}^{2} \mathrm{~g}^{-1}$ and pore size of $2.4 \mathrm{~nm}$, while a drastic change is observed when compared with the MS-NH surface area that was calculated to be $921.51 \mathrm{~m}^{2} \mathrm{~g}^{-1}$. Herein, the surface area decrease could be attributed to the successful 


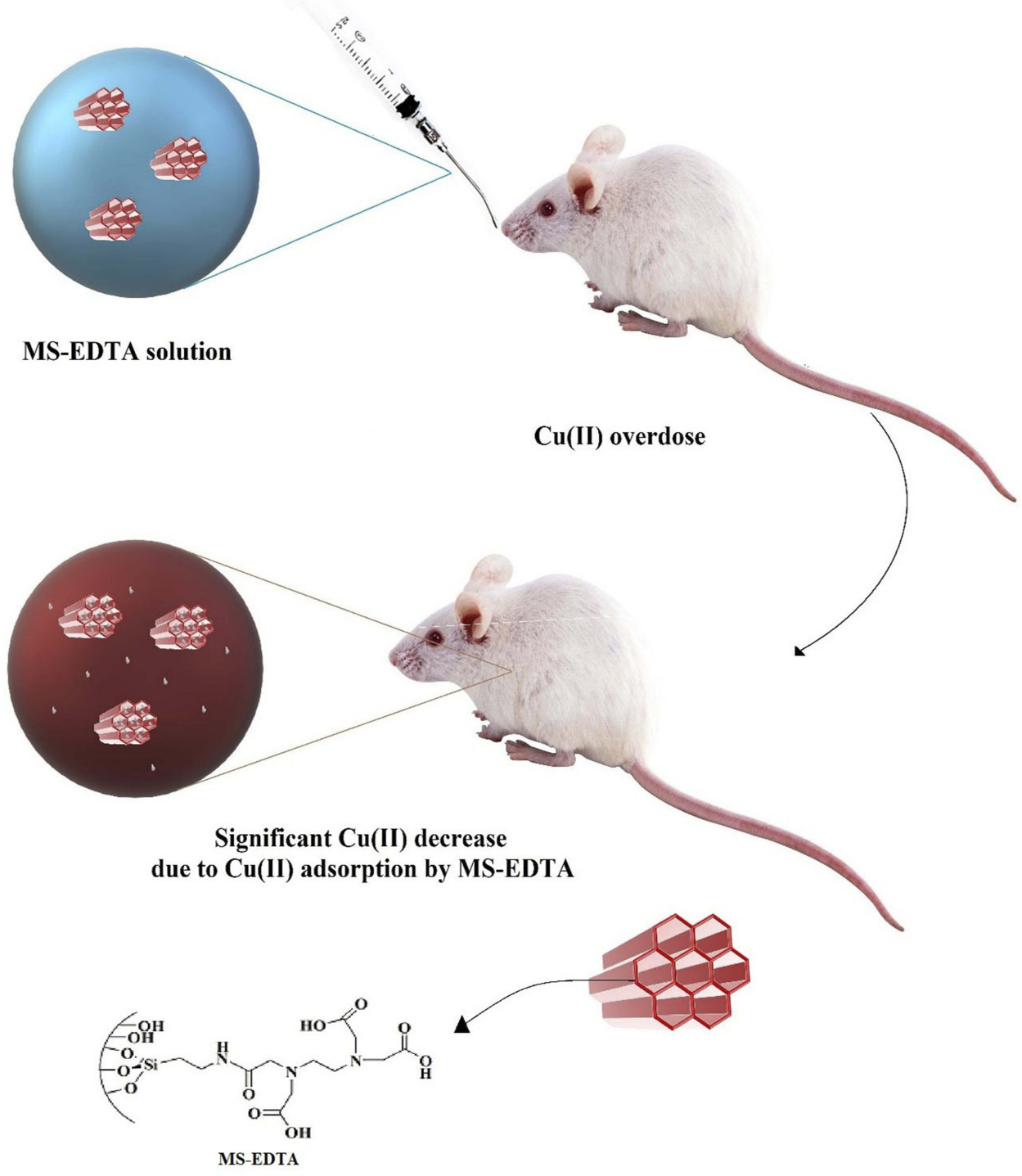

Figure I Schematic illustration of MS-EDTA administration in the treatment of copper toxicity. Abberviation: MS-EDTA, ethylenediaminetetraacetic acid modified mesoporous silica.

introduction of EDTA in MS-NH $\mathrm{NH}_{2}$ pores. The MS-EDTA crystallographic information which was received by low angle XRD has shown the expected crystallinity of mesoporous material by revealing a sharp peak at $0.8^{\circ}$ for the (100) xyz directions and a broader peak at $2.5^{\circ}$ resulting from additional Brag reflections (Figure 3).

The MS-EDTA morphological features, size, and shape, are investigated using FE-SEM (Figure 4) and HR-TEM (Figure 5) images. The FE-SEM image of MS-EDTA shows that most of the particles have a spherical shape and are monodispersed. These observations reveal that particles have sizes less than $500 \mathrm{~nm}$ with rough surfaces. In addition, TEM images confirm the formation of spherical porous structures with well-ordered pores. Also, EDX analysis was carried out to determine the amount of organic layer formation (i.e. aminopropyl and EDTA) in the MS-EDTA walls (Figure 6).

DLS provides the average size of nano-spheres based on the intensity of particles in the fluid environment. The average particle size in the sample is about $471 \mathrm{~nm}$ (Figure 7).

\section{Cu adsorption}

Based on the results, $\mathrm{Cu}$ adsorption percentage by the MS in pH 1.2 and 7.2 is found to be higher than $80 \%$ and $95 \%$, 


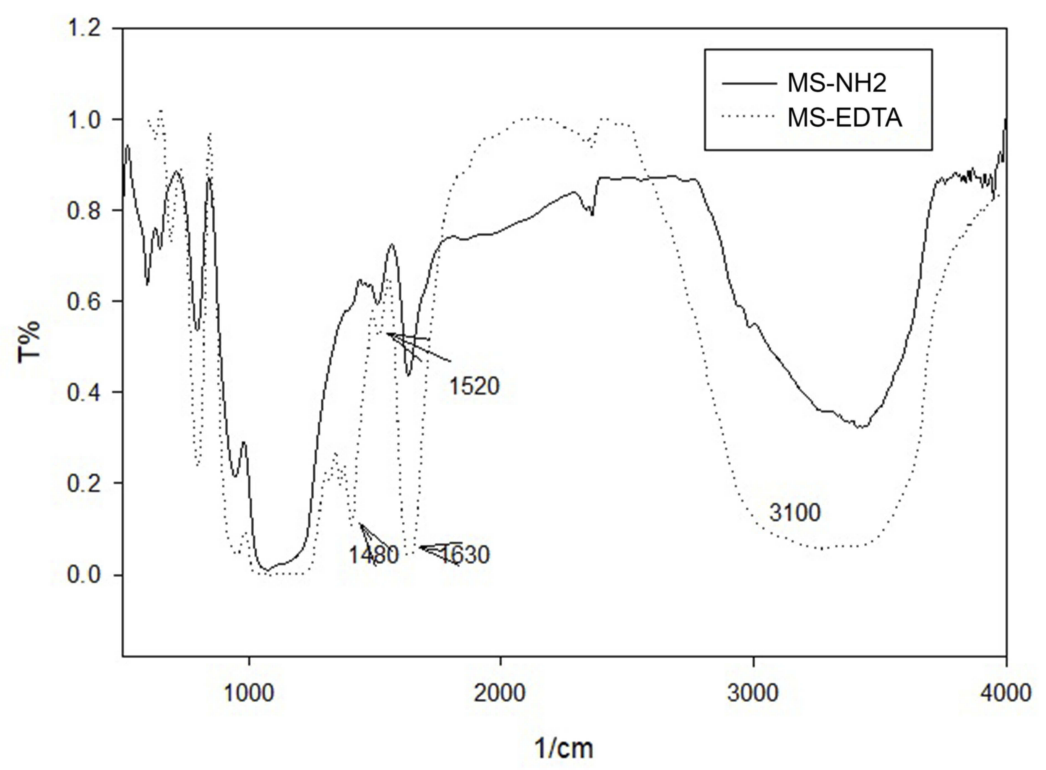

Figure 2 FT-IR spectroscopy of MS-NH2 and MS-EDTA.

Abbreviations: FT-IR, fourier transform infrared; MS-EDTA, ethylenediaminetetraacetic acid modified mesoporous silica.

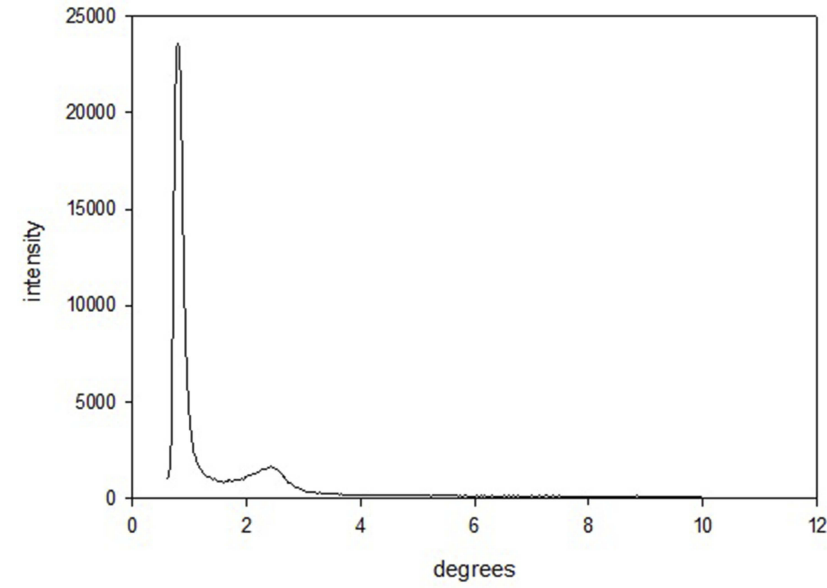

Figure 3 XRD pattern of MS-EDTA.

Abbreviations: $X R D, X$-ray diffraction; MS-EDTA, ethylenediaminetetraacetic acid modified mesoporous silica.

respectively. Results are shown in Figure 8(A, B). In vitro adsorption evaluations were carried out in $\mathrm{pH} 1.2$ (the same as $\mathrm{pH}$ of stomach environment) and $\mathrm{pH} 7.2$ (the same as intestinal $\mathrm{pH}$ ). The adsorption isotherm graphs are plotted based on the amount of $\mathrm{q}(\mathrm{mmol} / \mathrm{g})$ against the concentration of copper in equilibrium $\left(\mathrm{mmol} \mathrm{L}^{-1}\right)$. Adsorption is described in a wide range of concentrations. Figure $9(\mathrm{~A}, \mathrm{~B})$ indicates adsorption data that is fitted with Langmuir and Freundlich adsorption models, so the parameters extracted from the three models and their comparison are given in Table 1.

Using the Redlich-Peterson model $(\mathrm{n}<1)$, it is determined that copper adsorption by MS follows the Freundlich model with multi-layer adsorption. In this

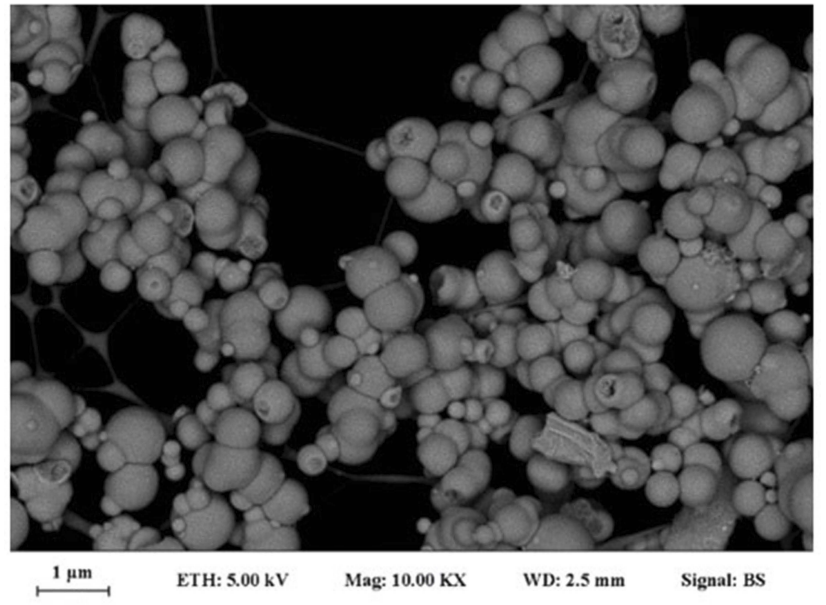

Figure 4 FE-SEM image of MS-EDTA.

Abbreviations: FE-SEM, field emission-scanning electron microscopy; MS-EDTA, ethylenediaminetetraacetic acid modified mesoporous silica.

way, with the formation of the primary EDTA complexes with $\mathrm{Cu}$ (II) and the entry of the sulfide ions, it is created to absorb other copper ions, and copper ions can be embedded in multi-layers of the MS-EDTA.

\section{Kinetic models}

Three kinetic models of the pseudo-first-order, pseudosecond-order, and intraparticle diffusion were used to investigate copper adsorption by MS-EDTA that are shown in Figures 8-12. The results show that $\mathrm{Cu}$ (II) adsorption by the MS-EDTA in the first 2 hrs corresponds to the intraparticle diffusion model. At this time, $\mathrm{Cu}(\mathrm{II})$ 


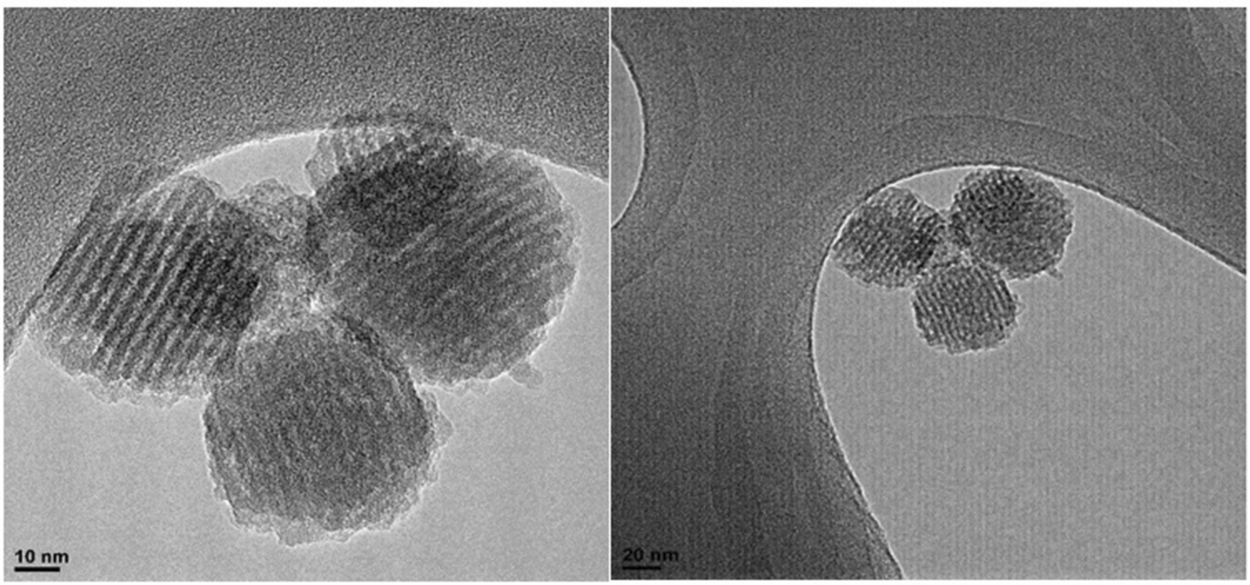

Figure 5 HR-TEM images of MS-EDTA.

Abbreviations: HR-TEM, high resolution-transmission electron microscopy; MS-EDTA, ethylenediaminetetraacetic acid modified mesoporous silica.

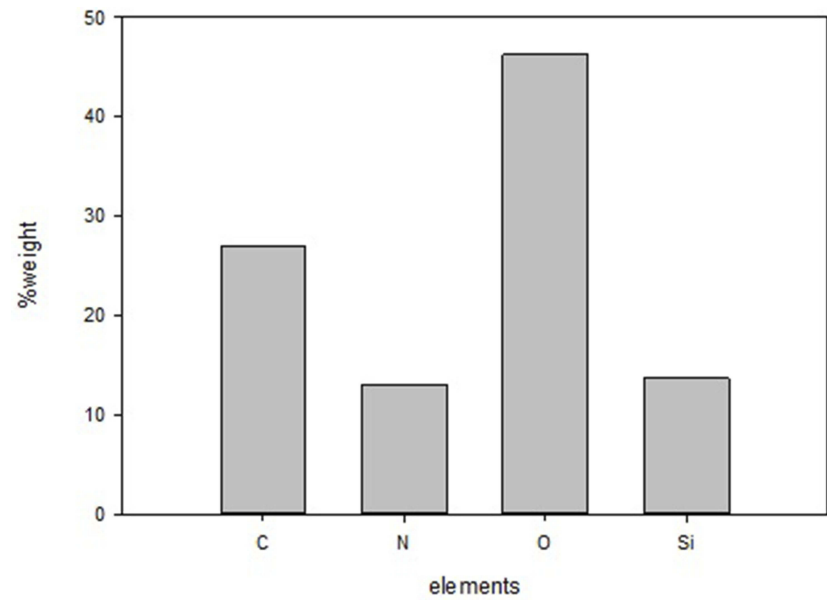

Figure 6 EDX analysis of MS-EDTA.

Abbreviations: EDX, energy-dispersive X-ray spectroscopy; MS-EDTA, ethylenediaminetetraacetic acid modified mesoporous silica.

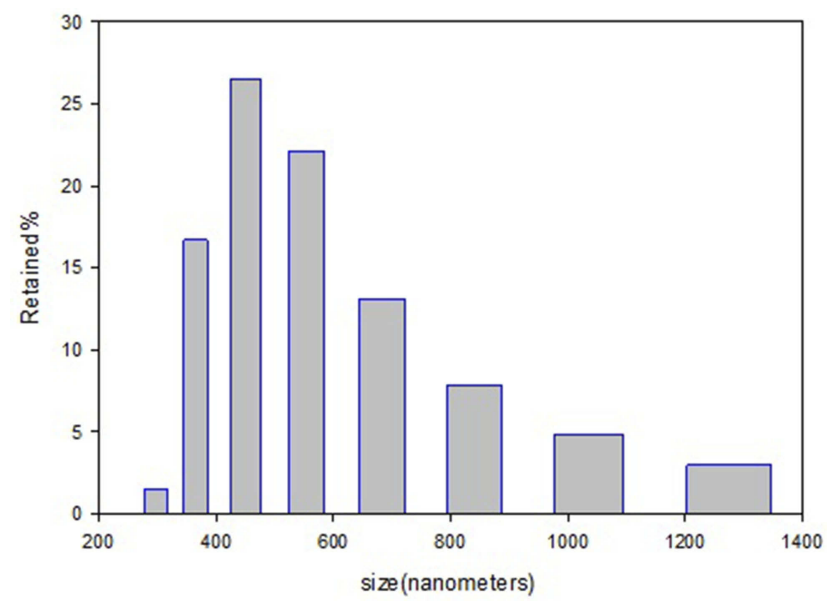

Figure 7 Particle size distribution histogram of MS-EDTA.

Abbreviation: MS-EDTA, ethylenediaminetetraacetic acid modified mesoporous silica. enter the MS-EDTA pores without interacting with functional groups and then conforms to the pseudo-secondorder model, the $\mathrm{Cu}$ (II) could bond to the functional groups in the porosity and the adsorption increases. The parameters obtained from the pseudo-second-order kinetic model are shown in Table 2.

\section{In vivo animal model}

Herein, an animal in vivo study attempts to evaluate the $\mathrm{Cu}$ adsorption efficiency of MS-EDTA in Cu-overdosed mice. In this case, an animal model of acute copper poisoning was prepared by IV injection of copper sulfate $(5000 \mathrm{mg} / \mathrm{kg})$ to the mice. As a result, the $\mathrm{Cu}$ level of serum and plasma markers of liver injury, including LDH, ALT, and AST were elevated in the Cu-treated group. As it was discovered, serum $\mathrm{Cu}$ and the biomarkers of injury in $\mathrm{Cu}$-treated mice are significantly reduced by administration of either EDTA or synthesized MS-EDTA. The effects of MS-EDTA were not dose-dependent in the current study (Figure 13). The MS-EDTA treated group was considerably more effective in comparison with EDTA. Although the serum $\mathrm{Cu}$ level in the antidote-treated mice is a bit higher than the control level, periodic antidote administration could bring normal serum $\mathrm{Cu}$ level back (Figure 14). Altogether, MS-EDTA $\mathrm{Cu}$ adsorption capability is a promising feature that could handle $\mathrm{Cu}$-overdose in cases such as Wilson disease treatment.

\section{Discussion}

MS-EDTA was synthesized by the co-condensation method and characterized. The nitrogen adsorption-desorption method illustrated type IV isotherm for MS-EDTA the 


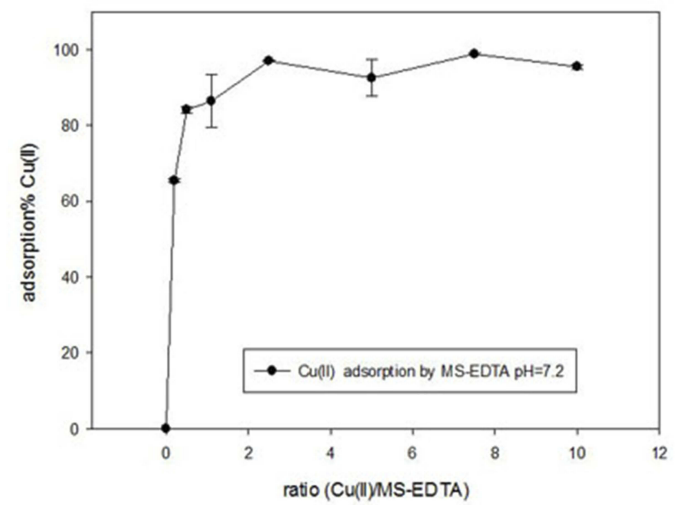

A

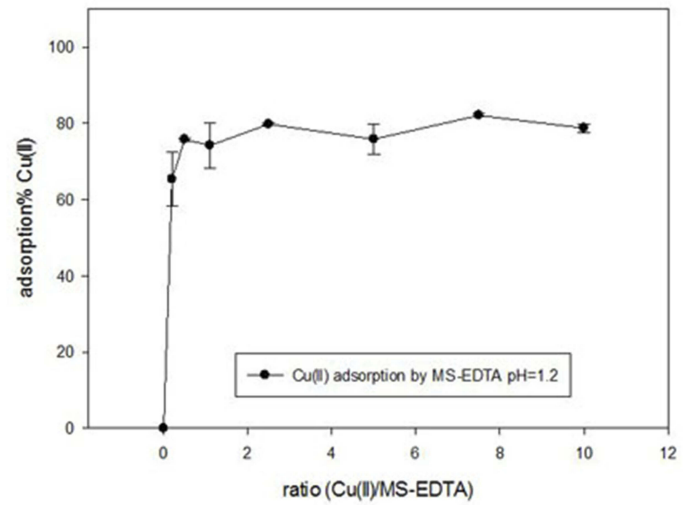

$\mathrm{B}$

Figure 8 Adsorption percentage of copper by MS-EDTA in pH 7.2 (A) and in pH I.2 (B)

Abbreviation: MS-EDTA, ethylenediaminetetraacetic acid modified mesoporous silica.

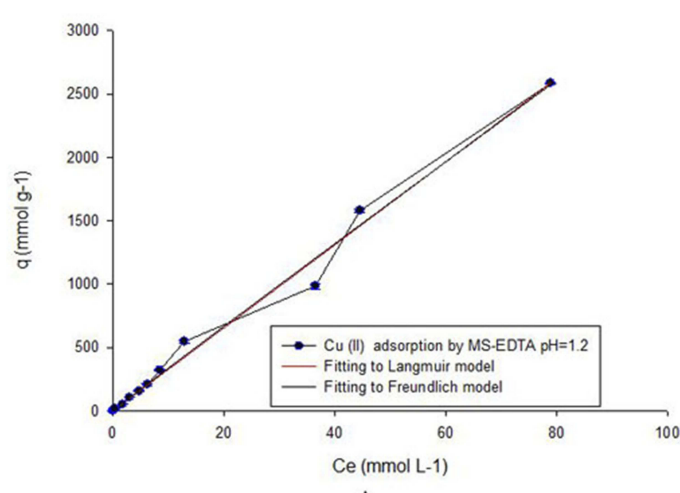

A

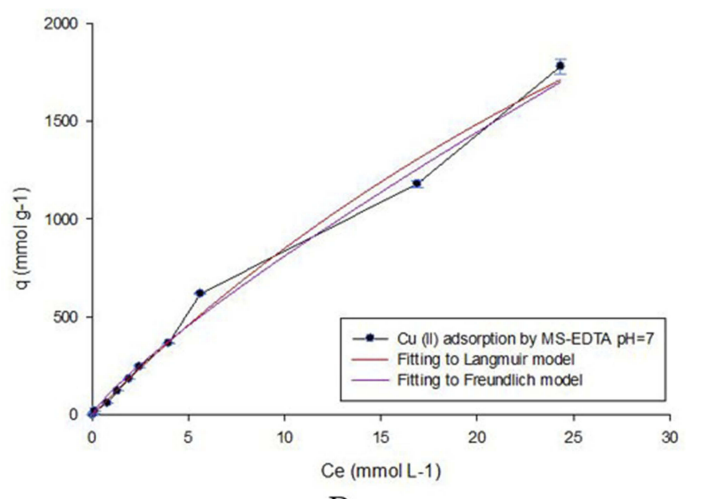

B

Figure 9 Adsorption isotherm of copper on MS-EDTA in aqueous media with $\mathrm{pH} 7.2$ (A) and in $\mathrm{pH}$ I.2 (B).

Abbreviation: MS-EDTA, ethylenediaminetetraacetic acid modified mesoporous silica.

Table I The parameters extracted from the three adsorption models and their comparison with Cu(II) adsorption on MS-EDTA

\begin{tabular}{|l|l|l|l|l|l|l|l|l|l|l|}
\hline & \multicolumn{3}{|l}{ Redlich-Peterson parameters } & \multicolumn{2}{l|}{ Freundlich parameters } & \multicolumn{2}{l|}{ Langmuir parameters } \\
\cline { 2 - 11 } & $\mathbf{A}$ & $\mathbf{B}$ & $\mathbf{g}$ & $\mathbf{R}^{\mathbf{2}}$ & $\mathbf{n}$ & $\mathbf{K}_{\mathbf{f}}$ & $\mathbf{R}^{\mathbf{2}}$ & $\mathbf{q}_{\mathbf{m}}$ & $\mathbf{K}_{\mathbf{~}}$ & $\mathbf{R}^{\mathbf{2}}$ \\
\hline MS-EDTA, pH=1.2 & 18,713 & 46 & 0.076 & 0.9923 & 293.75 & 519.44 & 0.9866 & $26,300.6$ & 0.0156 & 0.9919 \\
MS-EDTA, $\mathrm{pH}=7.2$ & $40,842 \times 10^{6}$ & $41 \times 10^{6}$ & 0.034 & 0.9906 & 244.13 & 1198.53 & 0.9945 & $45,023.3$ & 0.0245 & 0.9959 \\
\hline
\end{tabular}

Abbreviation: MS-EDTA, ethylenediaminetetraacetic acid modified mesoporous silica.

characteristic of the mesoporous structure. Also, using this method, the surface-to-volume ratio was about $352.35 \mathrm{~m}^{2} / \mathrm{g}$, the pore size was $2.4 \mathrm{~nm},{ }^{17}$ and the pore volume capacity was $0.11 \mathrm{~cm}^{3} / \mathrm{g}$. It should be noted that the surface area of the MS- $\mathrm{NH}_{2}$ was $921.51 \mathrm{~m}^{2} / \mathrm{g}$, which resulted in a significant decrease in EDTA loading. SEM shows spherical particle formation with less than $500 \mathrm{~nm}$ in size, and the DLS confirms this information $(471 \mathrm{~nm})$. Based on the TEM, it became clear that the particles had a porous morphology and a honeycomb structure. In a synthesized
MS-EDTA, a broad exponential peak in the reflection is observed in the region of 0.7 to about 1 in 2-theta, which is characterized by the MS structure and confirms the data obtained from the TEM. To investigate the presence of the desired functional groups at the internal surface of the porosity, FT-IR was performed, and it confirmed that the EDTA is bonded to the porosity surface and functional groups are available. On the other hand, based on the data obtained from thermogravimetric analysis, the amount of EDTA loaded in the MS cavities was $0.4 \mathrm{mmol} / \mathrm{g}$, which 


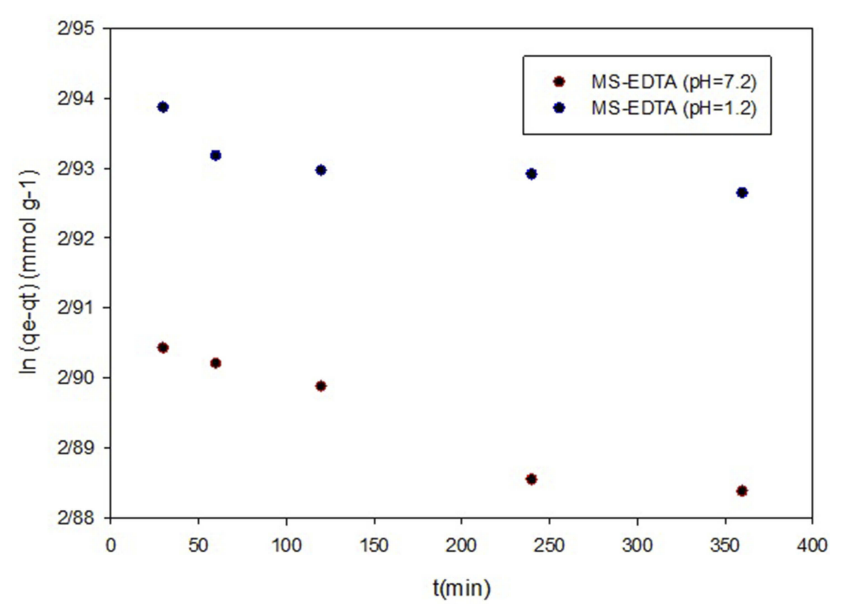

Figure 10 Pseudo-first-order model in $\mathrm{pH} 1.2$ and 7.2.

Abbreviation: MS-EDTA, ethylenediaminetetraacetic acid modified mesoporous silica.

fully matches the results of EDX. Particle efficiency was investigated for copper adsorption in $\mathrm{pH}=1.2$ and $\mathrm{pH}=7.2$. MS-EDTA in both media showed a high adsorption

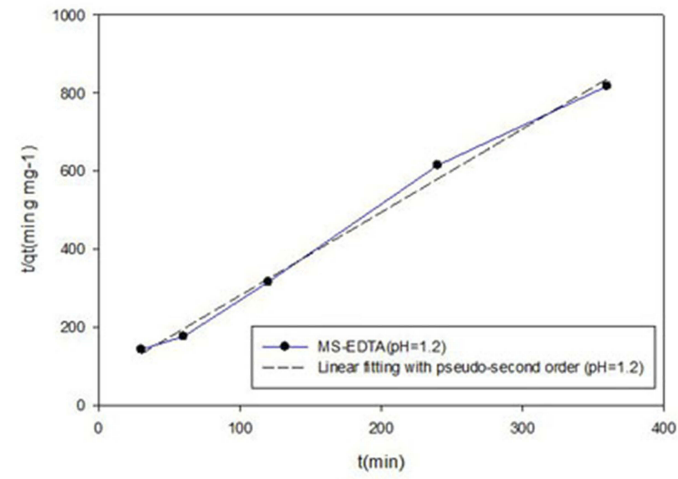

(A)

Figure II Pseudo-second-order model in $\mathrm{pH} 1.2(\mathbf{A})$ and $\mathrm{pH} 7.2$ (B).

Abbreviation: MS-EDTA, ethylenediaminetetraacetic acid modified mesoporous silica.

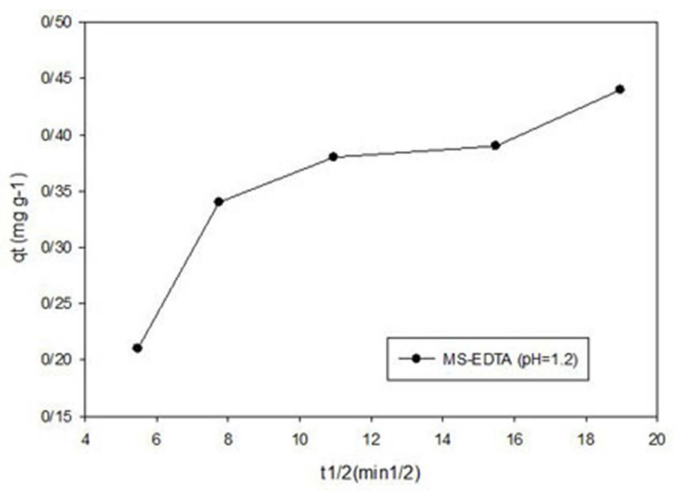

(A) capability for $\mathrm{Cu}$ (II) adsorption, however, because of the protonation of the amine group at $\mathrm{pH}=1.2$, in a medium with $\mathrm{pH}$ similar to the stomach area, it showed less adsorption and, conversely, in the environment with $\mathrm{pH}$ the same as the intestinal environment with $\mathrm{pH}=7.2$ shows a higher adsorption. The high adsorption of copper with MS-EDTA can be explained by the multi-layer adsorption of copper salt. The EDTA structure at $\mathrm{pH}=7.2$ has a negative charge and four non-protonated carboxyl groups that can be actively combined with copper. However, even with the protonation of the amine group in the acidic environment, MS-EDTA also shows good adsorption in $\mathrm{pH}=1.2$. In addition, the study of Langmuir, Freundlich, and Redlich-Peterson adsorption models showed that copper adsorption by MS-EDTA follows the Freundlich model with multi-layer adsorption, in which copper is adsorbed with EDTA and formed a complex between them. Following the formation of this complex, copper ions

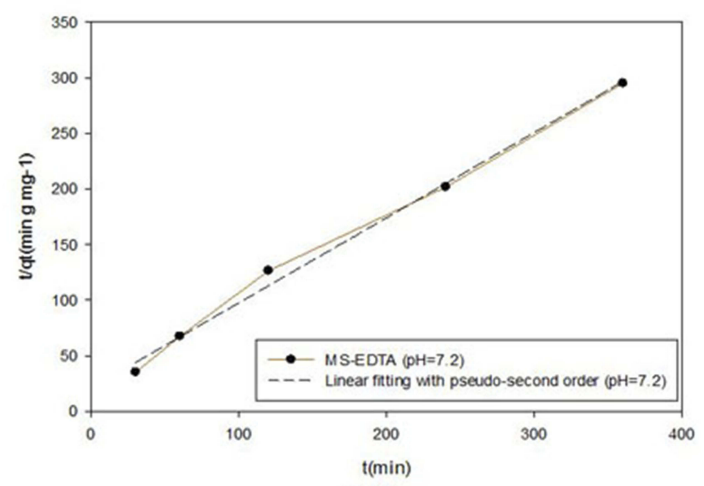

(B)

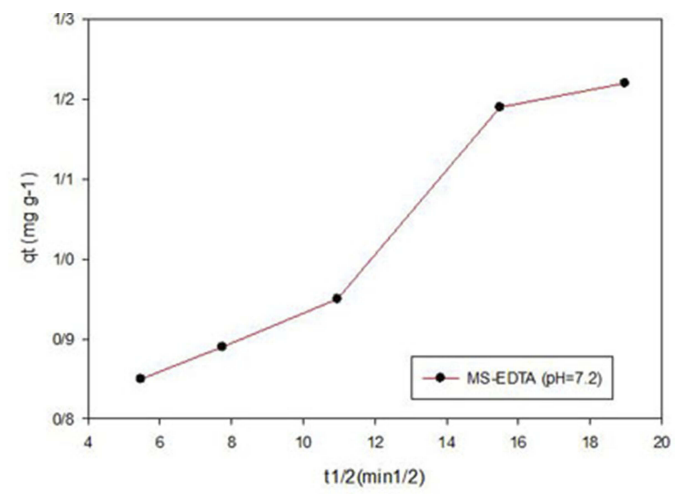

(B)

Figure 12 Intraparticle diffusion model; $(\mathbf{A}) \mathrm{pH} 7.2$ and $(\mathbf{B}) \mathrm{pH}$ I.2.

Abbreviation: MS-EDTA, ethylenediaminetetraacetic acid modified mesoporous silica. 
Table 2 Parameters derived from kinetic adsorption for MS-EDTA

\begin{tabular}{|l|l|l|l|}
\hline & $\mathbf{q}$ & $\mathbf{K}_{\mathbf{2}}$ & $\mathbf{R}^{\mathbf{2}}$ \\
\hline MS-EDTA, $\mathrm{pH}=1.2$ & 0.47 & 0.003 & 0.99 \\
MS-EDTA, $\mathrm{pH}=7.2$ & 1.34 & 0.082 & 0.99 \\
\hline
\end{tabular}

Abbreviation: MS-EDTA, ethylenediaminetetraacetic acid modified mesoporous silica.

adsorb sulfate ions and allow the re-adsorption of another layer of copper ions onto sulfate ions, which greatly increases the adsorption capacity. The study of three kinetic models, pseudo-first-order, pseudo-second-order, and intraparticle diffusion, showed that copper adsorption by MSEDTA in the first $2 \mathrm{hrs}$ complies with the intraparticle diffusion model. During this time, copper ions enter the MS pores without interacting with functional groups. After that corresponds to the pseudo-second-order model, at which time the copper ions with the functional groups in the porosity bonded and the adsorption increased. In vivo evaluation showed that MS-EDTA could be recognized as a potent antidote agent in acute copper poisoning. Although EDTA could reduce the $\mathrm{Cu}$ level of plasma but significant results obtained by treatment with MS-EDTA. On the other hand, as MS-EDTA particle might show an affinity for other metal ions rather than $\mathrm{Cu},{ }^{31}$ disturbances in vital metal ions (e.g. Fe, $\mathrm{Mg}$, and $\mathrm{Zn}$ ) might occur in their chronic administration (e.g. in experimental models of Wilsons disease). Hence, these metal ions could be administered as supplementary agents to prevent electrolytes and ion disturbances.

\section{Conclusion}

We conclude that EDTA-functionalized MS is spherical particles which were synthesized in co-condensation method and with well-ordered honeycomb pores, have an eligible

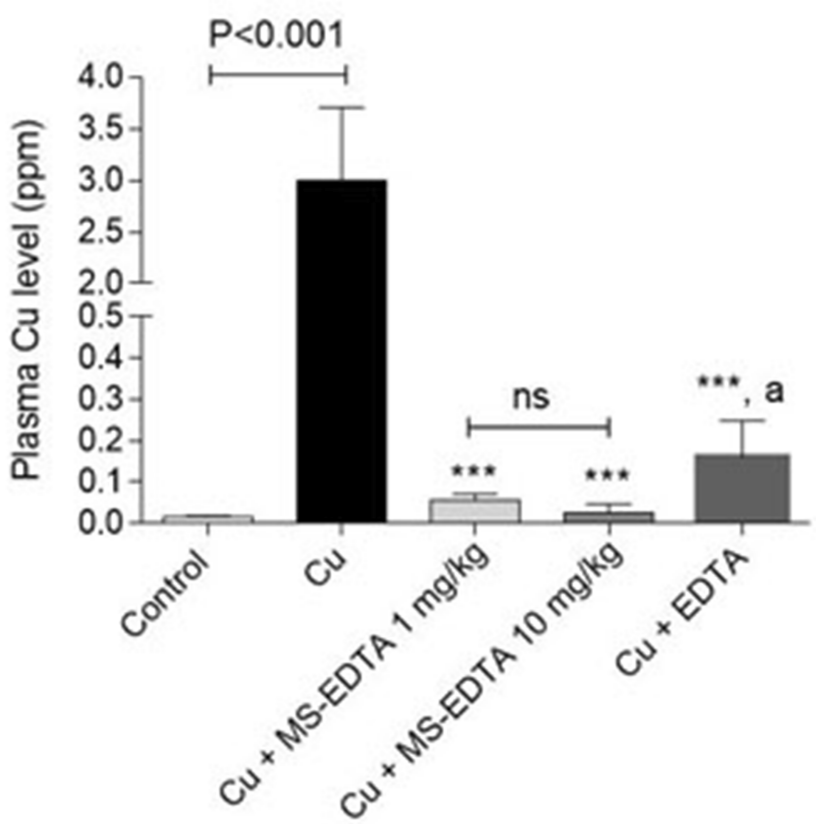

Figure I 4 Serum $\mathrm{Cu}(\mathrm{II})$ level in overdosed mice. ***Indicates significantly different as compared with the $\mathrm{Cu}$ group $(P<0.00 \mathrm{I})$. "a" indicates significantly different as compared with MS-EDTA-treated groups $(P<0.01)$.

Abbreviations: MS-EDTA, ethylenediaminetetraacetic acid modified mesoporous silica; ns, not significant.

surface-to-volume ratio, pore size, and the pore volume capacity for effective adsorption of copper ions. Particle efficiency was investigated for copper adsorption in $\mathrm{pH}=1.2$ (same as stomach environment $\mathrm{pH}$ ), and $\mathrm{pH}=7.2$ (same as intestinal environment $\mathrm{pH}$ ) and a high adsorption capability was observed in both media for copper adsorption, especially in $\mathrm{pH} 7.2$ medium which was much more satisfying attributed to the negatively charged functional groups. The in vivo evaluation showed the potential effect of MS-EDTA in the reduction of $\mathrm{Cu}$ plasma level in mice with $\mathrm{Cu}$ acute poisoning. Thus,
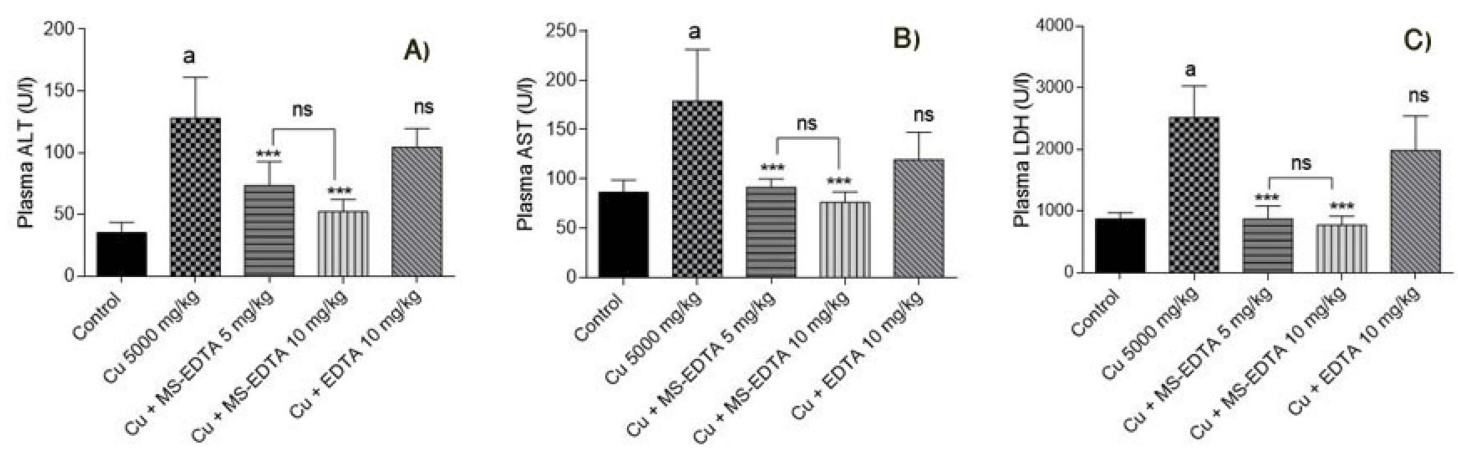

Figure 13 Plasma biomarkers of organ injury in copper-treated mice including (A) alanine aminotransferase (ALT), (B) aspartate aminotransferase (AST), and (C) lactate dehydrogenase $(\mathrm{LDH})$ along with $\mathrm{Cu}$ level were assessed $24 \mathrm{hrs}$ after $\mathrm{Cu}$ administration. Data are presented as mean \pm SD ( $\mathrm{n}=6$ ). $* * * I n d i c a t e s$ significantly different as compared with the Cu group $(P<0.00 \mathrm{I})$ "a" indicates significantly different as compared with the control group $(P<0.05)$.

Abbreviations: MS-EDTA, ethylenediaminetetraacetic acid modified mesoporous silica; ns, not significant. 
MS-EDTA can be recognized as an antidote of copper poisoning cases. On the other hand, these particles might be useful for decreasing complications associated with $\mathrm{Cu}$ accumulation in the body (e.g. in Wilson's disease). Therefore, evaluating the biological activity of MS particles in experimental models of Wilson's disease might help to develop safe therapeutic options against this complication in humans.

\section{Acknowledgment}

The authors would like to thank the Research Council of Shiraz University of Medical Science for supporting this work under grant No.1396-01-74-14350.

\section{Disclosure}

The authors report no conflicts of interest in this work.

\section{References}

1. Whitesides GM. Nanoscience, nanotechnology, and chemistry. Small. 2005;1:172-179. doi:10.1002/smll.200400130

2. Brigger I, Dubernet C, Couvreur P. Nanoparticles in cancer therapy and diagnosis. Adv Drug Deliv Rev. 2012;64:24-36. doi:10.1016/j. addr.2012.09.006

3. Farjadian F, Moghoofei M, Mirkiani S, et al. Bacterial components as naturally inspired nano-carriers for drug/gene delivery and immunization: set the bugs to work? Biotechnol Adv. 2018;36(4):968-985. doi:10.1016/j.biotechadv.2018.02.016

4. Park K. Controlled drug delivery systems: past forward and future back. J Controlled Release. 2014;190:3-8. doi:10.1016/j.jconrel.2014.03.054

5. Edgar JYC, Wang H. Introduction for design of nanoparticle based drug delivery systems. Curr Pharm Des. 2017;23(14):2108-2112. doi:10.2174/1381612822666161025154003

6. Lamichhane N, Udayakumar T, D'Souza W, et al. Liposomes: clinical applications and potential for image-guided drug delivery. Molecules. 2018;23(2):288. doi:10.3390/molecules23020288

7. Hosseini M, Farjadian F, Makhlouf ASH. Smart stimuli-responsive nano-sized hosts for drug delivery. Industrial Applications Intelligent Polym Coat. 2016;1-26. doi.org/10.1007/978-3-319-26893-4_1

8. Noriega-Luna B, Godínez LA, Rodríguez FJ, et al. Applications of dendrimers in drug delivery agents, diagnosis, therapy, and detection. J Nanomater. 2014;2014:39. doi:10.1155/2014/507273

9. Dadfar SM, Roemhild K, Drude NI, et al. Iron oxide nanoparticles: diagnostic, therapeutic and theranostic applications. Adv Drug Deliv Rev. 2019;138:302-325. doi:10.1016/j.addr.2019.01.005

10. Hornos Carneiro MF, Barbosa JF. Gold nanoparticles: a critical review of therapeutic applications and toxicological aspects. $J$ Toxicol Environ Health Part B. 2016;19(3-4):129-148. doi:10.10 80/10937404.2016.1168762

11. Medintz IL, Mattoussi H, Clapp AR. Potential clinical applications of quantum dots. Int $J$ Nanomedicine. 2008;3(2):151.

12. Ahmed W, Elhissi A, Dhanak V, Subramani K. Chapter 18 - carbon nanotubes: applications in cancer therapy and drug delivery research. Emerging Nanotechnol Dent. 2nd ed.; Subramani, K., Ahmed, W. Eds. 371-389. doi:10.1016/B978-0-12-812291-4.00018-2

13. Baeza A, Ruiz-Molina D, Vallet-Regí M. Recent advances in porous nanoparticles for drug delivery in antitumoral applications: inorganic nanoparticles and nanoscale metal-organic frameworks. Expert Opin Drug Deliv. 2017;14(6):783-796. doi:10.1080/17425247.2016.1229 298
14. Eurov DA, Kurdyukov DA, Stovpiaga EY, et al. Hypersonic properties of monodisperse spherical mesoporous silica particles. $J$ Phys $D$ Applied Phys. 2014;47(33):5. doi:10.1088/0022-3727/47/33/335303

15. Farjadian F, Roointan A, Mohammadi-Samani S, Hosseini M. Mesoporous silica nanoparticles: synthesis, pharmaceutical applications, biodistribution, and biosafety assessment. Chem Eng J. 2019;359:684-705. doi:10.1016/j.cej.2018.11.156

16. BernArdos A, KouřimsKá L. Applications of mesoporous silica materials in food-a review. Czech J Food Sci. 2013;31(2):99-107. doi:10.17221/240/2012-CJFS

17. He Q, Zhang Z, Gao F, Li Y, Shi J. In vivo biodistribution and urinary excretion of mesoporous silica nanoparticles: effects of particle size and PEGylation. Small. 2011;7(2):271-280. doi:10.1002/smll.201001459

18. Yang P, Gaib S, Lin J. Functionalized mesoporous silica materials for controlled drug delivery. Chem Soc Rev. 2012;41(9):3679-3698. doi:10.1039/c2cs15308d

19. ALOthman ZA. A review: fundamental aspects of silicate mesoporous materials. Materials (Basel). 2012;5(12):2874-2902. doi:10.339 $0 / \mathrm{ma} 5122874$

20. Mehmood A, Ghafar H, Yaqoob S, Gohar U, Ahmad B. Mesoporous silica nanoparticles: a review. J Dev Drugs. 2017;6(2):1000174. doi:10.4172/2329-6631.1000174.

21. Narayan R, Nayak U, Raichur A, Garg S. Mesoporous silica nanoparticles: a comprehensive review on synthesis and recent advances. Pharmaceutics. 2018;10(3):118. doi:10.3390/pharmaceutics10030118

22. Farjadian F, Hosseini M, Ghasemi S, Tamami B. Phosphinite-functionalized silica and hexagonal mesoporous silica containing palladium nanoparticles in Heck coupling reaction: synthesis, characterization, and catalytic activity. RSC Adv. 2015;5(97):7997679987. doi:10.1039/C5RA16131B

23. Duhan S, Tomer VK. Mesoporous silica: making "sense" of sensors. Adv Sensor Detect Mater. 2014;6:149-192. doi:10.1002/9781118 774038.ch6

24. Karimi M, Mirshekari H, Aliakbari M, Sahandi-Zangabad P, Hamblin MR. Smart mesoporous silica nanoparticles for controlled-release drug delivery. Nanotechnol Rev. 2016;5(2):195-207. doi:10.1515/ ntrev-2015-0057

25. Cha BG, Kim J. Functional mesoporous silica nanoparticles for bioimaging applications. Wiley Interdiscip Rev. 2019;11(1):e1515.

26. Abdelsamad AM, Khalil AS, Ulbricht M. Influence of controlled functionalization of mesoporous silica nanoparticles as tailored fillers for thin-film nanocomposite membranes on desalination performance. J Memb Sci. 2018;563:149-161. doi:10.1016/j.memsci.2018.05.043

27. Farjadian F, Azadi S, Mohammadi-Samani S, Ashrafi H, Azadi A. A novel approach to the application of hexagonal mesoporous silica in solid-phase extraction of drugs. Heliyon. 2018;4(11):e00930. doi:10. 1016/j.heliyon.2018.e00930

28. Cashin VB, Eldridge DS, Yu A, Zhao D. Surface functionalization and manipulation of mesoporous silica adsorbents for improved removal of pollutants: a review. Environ Sci. 2018;4(2):110-128.

29. Jacobsen D, Haines JA. The relative efficacy of antidotes: the IPCS evaluation series. International Programme on Chemical Safety. Arch Toxicol Suppl. 1997;19:305-310.

30. Farjadian F, Ahmadpour P, Samani S, Hosseini M. Controlled size synthesis and application of nanosphere MCM-41 as potent adsorber of drugs: a novel approach to new antidote agent for intoxication. Microporous Mesoporous Mater. 2015;213:30-39. doi:10.1016/j. micromeso.2015.04.002

31. Farjadian F, Ghasemi S, Heidari R, Mohammadi-Samani S. In vitro and in vivo assessment of EDTA-modified silica nano-spheres with supreme capacity of iron capture as a novel antidote agent. Nanomed. 2017;13(2):745-753. doi:10.1016/j.nano.2016.10.012

32. Kalantari S, Yousefpour M, Taherian Z. Synthesis of mesoporous silica/iron oxide nanocomposites and application of optimum sample as adsorbent in removal of heavy metals. Rare Metals. 2017;36 (12):942-950. doi:10.1007/s12598-016-0709-4 
33. Huang J, Ye M, Qu Y, et al. Pb (II) removal from aqueous media by EDTA-modified mesoporous silica SBA-15. J Colloid Interface Sci. 2012;385(1):137-146. doi:10.1016/j.jcis.2012.06.054

34. Ranucci G, Di Dato F, Leone F, Vajro P, Spagnuolo M, Iorio R. Penicillamine-induced elastosis perforans serpiginosa in wilson disease: is useful switching to zinc? J Pediatr Gastroenterol Nutr. 2017;64(3):e72-e73. doi:10.1097/MPG.0000000000000613

35. Yu H, Xie -J-J, Chen Y-C, et al. Clinical features and outcome in patients with osseomuscular type of Wilson's disease. BMC Neurol. 2017;17(1):34. doi:10.1186/s12883-017-0818-1

36. Favre E, Lion-François L, Canton M, et al. Cognitive abilities of children with neurological and liver forms of Wilson disease. $J$ Pediatr Gastroenterol Nutr. 2017;64(3):436-439.

37. Walshe J. Penicillamine neurotoxicity: an hypothesis. ISRN Neurol. 2011;2011. https://doi.org/10.5402/2011/464572

38. Etienne M, Lebeau B, Walcarius A. Organically-modified mesoporous silica spheres with MCM-41 architecture. $N J$ Chem. 2002;26 (4):384-386. doi:10.1039/b110741k
39. Ho Y-S. Isotherms for the sorption of lead onto peat: comparison of linear and non-linear methods. Pol J Environ Stud. 2006;15:1.

40. Farjadian F, Schwark S, Ulbricht M. Novel functionalization of porous polypropylene microfiltration membranes: via grafted poly (Aminoethyl methacrylate) anchored schiff base toward membrane adsorbers for metal ions. Polym Chem. 2015;6(9):1584-1593. doi:10.1039/C4PY01521E.

41. Chen Z, Meng H, Xing G, et al. Acute toxicological effects of copper nanoparticles in vivo. Toxicol Lett. 2006;163(2):109-120. doi:10.10 16/j.toxlet.2005.10.003

42. Heidari R, Mohammadi H, Ghanbarinejad V, et al. Proline supplementation mitigates the early stage of liver injury in bile duct ligated rats. J Basic Clin Physiol Pharmacol. 2019;30(1):91-101. doi:10.1515/jbcpp-20170221

\section{Publish your work in this journal}

The International Journal of Nanomedicine is an international, peerreviewed journal focusing on the application of nanotechnology in diagnostics, therapeutics, and drug delivery systems throughout the biomedical field. This journal is indexed on PubMed Central, MedLine, CAS, SciSearch ${ }^{\mathbb{R}}$, Current Contents ${ }^{\mathbb{R}} /$ Clinical Medicine, $^{-}$
Journal Citation Reports/Science Edition, EMBase, Scopus and the Elsevier Bibliographic databases. The manuscript management system is completely online and includes a very quick and fair peer-review system, which is all easy to use. Visit http://www.dovepress.com/ testimonials.php to read real quotes from published authors. 